\title{
A IMPORTÂNCIA DA GESTÃO ESTRATÉGICA NO RECRUTAMENTO E SELEÇÃO DE PESSOAL NAS ORGANIZAÇÕES
}

THE IMPORTANCE OF STRATEGIC MANAGEMENT IN THE RECRUITMENT AND SELECTION OF STAFF IN ORGANIZATIONS

Fabiano Greter Moreira

Universidade Federal de Mato Grosso do Sul, Nova Andradina, RS, Brasil E-mail: fabiano.gm12@hotmail.com

Recebido em: 01.04.2017 - Aceito em: 15.07.2017

\section{RESUMO}

No presente artigo, apresentaram-se as bases científicas da gestão de recrutamento e seleção de pessoal no âmbito organizacional, com várias formas e alternativas de como recrutar e selecionar seu capital intelectual. As práticas estão integradas diariamente no serviço de recrutamento e seleção de colaboradores da empresa. O papel do recrutamento e seleção de pessoal é fundamental em todo o processo organizacional, criando e estimulando políticas e ações que visem reduzir os custos operacionais em admissões e demissões de funcionários. O objetivo do trabalho é descrever conceitos e procedimentos utilizados no recrutamento e seleção de pessoal nas organizações, propondo maior eficiência e agilidade nas contratações. Foi realizada pesquisa bibliográfica, com a finalidade de explorar a temática, visando problematizar a importância da gestão estratégica de recrutamento e seleção de pessoal nas empresas. Os principais resultados obtidos referem-se aos diversos métodos e técnicas que podem ser aplicados no âmbito do recrutamento e seleção de pessoal, propiciando maior eficiência aos responsáveis pelas contratações, bem como a seleção, de maneira mais adequada, das pessoas às funções que desempenharão, contribuindo com o processo produtivo da organização e definindo o perfil de cada vaga ao candidato pretendido, de modo a reduzir o nível de demissões nas organizações.

PALAVRAS-CHAVE: Candidatos; Estratégia; Pessoas; Técnicas.

\section{ABSTRACT}

In this article, we present the scientific bases of the management of recruitment and selection of personnel in the organizational scope, with various forms and alternatives of how to recruit and select their intellectual capital. The practices are integrated daily in the service of Recruitment and Selection of Employees of 
the company. The role of recruitment and selection of staff is critical throughout the organizational process, creating and stimulating policies and actions that aim to reduce operational costs in admissions and dismissals of employees. The objective of this work is to describe concepts and procedures used in the recruitment and selection of personnel in organizations, proposing greater efficiency and agility in hiring. A bibliographical research was used to explore the theme, aiming to problematize the importance of strategic management of recruitment and selection of personnel in companies. The main results obtained were the various methods and techniques that can be applied in the scope of recruitment and selection of personnel, providing greater efficiency to those responsible for hiring, as well as selecting people in a more appropriate way to the functions they will perform, contributing to the process Productive, and defining the profile of each vacancy for the intended candidate, thus reducing the level of layoffs in organizations.

KEYWORDS: Candidates; Strategy; People; Techniques.

\section{INTRODUÇÃO}

A área de Recursos Humanos, no âmbito de recrutamento e seleção, busca basicamente compatibilizar as necessidades de curto prazo das pessoas com os objetivos de longo prazo nas organizações, enfatiza Chiavenato (2002). No modelo de comprometimento, enfatizam-se a flexibilidade e a boa comunicação e supõe-se que as pessoas acreditam nas mensagens da gerência e estão dispostas a aceitar desafios.

O recrutamento e seleção na Gestão de Recursos Humanos nada mais é que proporcionar a melhor adequação da função com o candidato selecionado, a fim de que apresente um melhor desempenho e maior produtividade e diminua o seu tempo de integração dentro da organização.

Para ser eficaz, Chiavenato (2002) sintetiza que o recrutamento deve atrair um contingente de candidatos suficiente para abastecer adequadamente o processo de seleção. Aliás, a função do recrutamento é a de suprir a seleção de matéria-prima (candidatos) para seu funcionamento. A seleção de pessoas faz parte do processo de previsão de pessoal, vindo logo depois do recrutamento. A seleção é uma atividade obstativa, de escolha, de classificação e, portanto, restritiva.

A estratégia de recrutamento pode estar direcionada para duas vertentes: recrutamento interno (procurar o candidato dentro da mesma empresa) ou recrutamento externo (procurar o candidato no mercado). O Departamento de Re- 
cursos Humanos, ou a pessoa responsável pelo processo, deve definir, como o primeiro passo do recrutamento, o perfil pretendido para a função.

Segundo Gil (2001), os requisitos considerados indispensáveis devem ser mantidos em quantidade mínima, para não afastar os candidatos com potencial. $O$ mais importante na maioria dos casos não é a qualidade atual do candidato, mas o seu potencial para a função, aliado à sua vontade de trabalhar e de aprender.

O desenvolvimento pessoal e empresarial de um colaborador depende de seu aperfeiçoamento e desempenho motivacional próprio. Nesse sentido, a Gestão de Recursos Humanos tem que estar atenta às inovações e proporcionar condições favoráveis para o crescimento dos seus colaboradores.

O recrutamento e seleção de pessoal proporciona condições relevantes para o desempenho profissional e competitivo das organizações. O processo, ao ser realizado de acordo com técnicas e formas apropriadas, levando em consideração as características da vaga/função, somadas ao perfil do candidato em potencial, possibilita maior adequação deste à atividade laboral. Essa conjuntura entre o candidato e a função/vaga atribui forças possíveis de aptidão e rapidez à cultura da empresa e ao posto de trabalho pretendido. Diante dessas possibilidades que a gestão do recrutamento e seleção de pessoal permite às organizações, pergunta-se: quais são os processos e técnicas para a efetivação do recrutamento e seleção de pessoal nas organizações?

O objetivo do trabalho é apresentar a importância da gestão estratégica no âmbito do recrutamento e seleção de pessoas nas organizações, evidenciando as ferramentas e as técnicas utilizadas para atrair novos colaboradores.

\section{REFERENCIAL TEÓRICO}

É comum serem confundidos os termos "recrutamento" e "seleção", embora não sejam sinônimos. A fase de recrutamento refere-se ao processo que decorre entre a decisão de contratar um colaborador até a recepção de candidatos. Já a seleção é o processo que resulta da escolha dos candidatos que preenchem o perfil requerido até a escolha final e definitiva do candidato. Contudo, antes de ser preenchido o lugar vago, devem ser encaradas outras alternativas, tais como: (Chiavenato, 2002, p. 222).

- redistribuição das tarefas atribuídas a esse cargo a outros membros da empresa;

- análise das diferentes funções do mesmo departamento, para aferir se há tarefas que podem ser eliminadas ou automatizadas. 
Se, no final dessa análise, ainda persistir a necessidade de recrutamento de um novo colaborador para a empresa, então será preciso ter em conta:

- se o custo adicional de um novo colaborador está orçamentado;

- a partir de que data será realmente necessário que o novo colaborador inicie as suas funções.

Segundo Gil (2001, p. 93-94), "com base na descrição da função, o selecionador define o perfil do candidato. Com isso, passa-se então ao recrutamento, processo que visa atrair os candidatos para ocupar os cargos dentro da empresa".

Existem vários meios de atrair o candidato para o recrutamento, entre os quais se destacam os seguintes:

1. recrutamento interno;

2. cartazes;

3. recomendação;

4. pessoal dispensado;

5. agências;

6. associações profissionais;

7. anúncios;

8. headhunters (caça talentos);

9. internet.

A respeito da Política de Provisão de Recrutamento e Seleção, podem-se citar os seguintes fatores:

a. onde recrutar (fontes de recrutamento dentro ou fora da organização), em que condições e como recrutar (técnicas de recrutamento preferidas pela organização para abordar o mercado de recursos humanos) os recursos humanos necessários à organização;

b. critérios de seleção de recursos humanos e padrões de qualidade para admissão, quanto às aptidões físicas e intelectuais, experiência e potencial de desenvolvimento, tendo-se em vista o universo de cargos dentro da organização. (Chiavenato, 1999, p. 173-174). 


\subsection{Conceito de recrutamento de pessoal}

Recrutamento de pessoal é uma atividade de responsabilidade do sistema de Administração de Recursos Humanos (ARH), que tem por finalidade a captação de recursos humanos interna e externamente à organização, objetivando municiar o subsistema de seleção de pessoal no atendimento aos clientes internos da empresa (Marras, 2009, p. 69).

O recrutamento abrange o conjunto de práticas e processos usados para atrair candidatos para as vagas existentes ou potenciais. Só é possível recrutar a pessoa certa se soubermos antecipadamente o perfil desejado, isto é, "as características pessoas e profissionais". O êxito no processo de recrutamento depende desse perfil bem definido. Para isso, é preciso saber o que se espera do candidato, isto é, o que ele vai fazer. Tais características são estabelecidas na descrição das funções, que tem como um dos objetivos proporcionar informações para facilitar o recrutamento, a seleção e o reposicionamento das pessoas adequadas para cada função (Lacombe, 2005, p. 66-67).

\subsection{Processo de recrutamento}

Todo processo de recrutamento de pessoal tem início a partir de uma necessidade interna da organização, no que tange à contratação de novos profissionais. Essa necessidade, que, como vimos, origina-se por motivos diversos, é expressa ou emitida formalmente, pelo "requisitante" da área, através de um documento denominado de Requisição de Pessoal (RP). Em linhas gerais, a RP segue um fluxo predeterminado pela própria organização (Figura 1), mas, em geral, o que determina o seu atendimento automático é a sua própria razão de ser, seja por motivo de substituição, seja por aumento de quadro (Marras, 2009, p. 69-70).

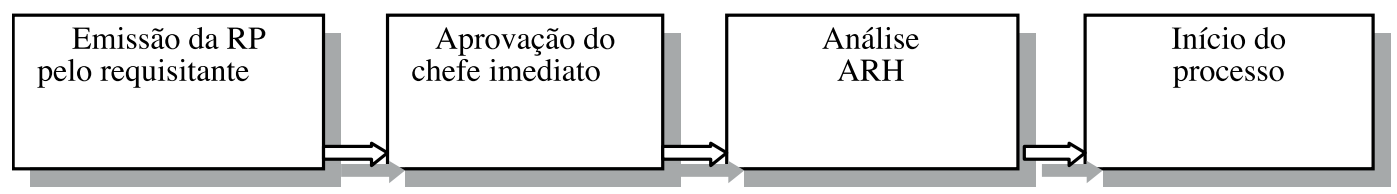

Figura 1 - Fluxo da Requisição de Pessoal - RP

Fonte: adaptada de Marras (2009).

\subsection{Fontes de recrutamento}

Fontes de recrutamento são as instâncias que devem ser exploradas na busca de recursos humanos para abastecer o processo seletivo da empresa. Entre as fontes de recrutamento mais utilizadas, destacam-se as apresentadas no quadro 1 (Marras, 2009, p. 71). 


\begin{tabular}{|l|}
\hline Tipos de fontes de recrutamento \\
\hline $1-$ Funcionários da própria empresa \\
\hline $2-$ Banco de dados interno \\
\hline $3-$ Indicações \\
\hline $4-$ Cartazes (internos e externos) \\
\hline $5-$ Entidades (sindicatos, associações, etc.) \\
\hline 6 - Escolas, universidades, cursos, etc. \\
\hline 7 - Outras empresas (fornecedores, clientes, etc.) \\
\hline 8 - Consultorias \\
\hline $9-$ Agências de empregos \\
\hline $10-$ Mídia (anúncios classificados, rádio, televisão, etc.) \\
\hline $11-$ Headhunters \\
\hline
\end{tabular}

Quadro 1 - Fontes de recrutamento

Fonte: adaptado de Marras (2009).

Para Chiavenato (2002, p. 224), "a estratégia de recrutamento pode estar direcionada para duas vertentes: recrutamento interno (procurar o candidato dentro da mesma empresa); ou recrutamento externo (procurar o candidato no mercado)".

\subsection{Recrutamento interno}

É aquele que privilegia os próprios recursos da empresa. Isto é, a divulgação das necessidades (vagas em aberto) é informada por meio de comunicação - memorando ou cartazes -, em todos os quadros de avisos da empresa, com as características exigidas pelo cargo, solicitando àqueles interessados que compareçam ao setor de recrutamento para candidatar-se à posição oferecida ou enviar seus dados para a análise. (Marras, 2009, p. 71-72).

Ressalva Chiavenato (2002) que o recrutamento interno tem as suas vantagens e potencialidades:

- o custo é menor do que o recurso ao mercado externo;

- a pessoa já está integrada na organização;

- pode significar um progresso na carreira.

Afirma ainda o mesmo autor que o processo é mais lento nesse tipo de recrutamento, pois implica a substituição do funcionário que vai preencher o lugar vago. Além disso, o colaborador selecionado é normalmente um bom e exemplar funcionário (é uma forma de promoção), podendo a sua transferência provocar alguma relutância por parte da chefia de topo. Ainda, ao rejeitar alguns dos candi- 
datos internos, é fundamental saber gerir com sucesso as expectativas frustradas, mantendo a motivação da equipe.

De acordo com Lacombe (2005, p. 68-69), o aproveitamento do pessoal da empresa tem as seguintes vantagens: motiva todos os empregados, sinalizando a disposição de se promover a "prata da casa" e de se criar perspectivas de carreira; no longo prazo, facilita o recrutamento de pessoas mais qualificadas; costuma ser mais rápido, pois as pessoas estão disponíveis e as vagas são preenchidas mais depressa; o custo de admissão é praticamente nulo; se houver uma boa avaliação dos candidatos, a probabilidade de acerto tende a ser maior, uma vez que eles já estão na empresa e são conhecidos; aproveita melhor o treinamento do pessoal; e diminui a probabilidade de rejeição pelos colegas.

Para a obtenção dessas vantagens, porém, é necessária uma boa avaliação do pessoal. Existem inúmeros exemplos de promoções malsucedidas por falta de conhecidos. Se o processo de promoções não for bem administrado e bem comunicado, pode gerar frustrações nos que não forem promovidos. Basta pensar que, ao recrutar um empregado dos próprios quadros da organização, a empresa se beneficia nos seguintes pontos (Marras, 2009, p. 72):

- a velocidade do processo de recrutamento e seleção é otimizada ao extremo: os interessados comparecem de imediato ao setor de R\&S e em no máximo 24 horas já podem estar sendo avaliados pelo requisitante. $\mathrm{A}$ avaliação pela intranet pode ser imediata;

- o processo admissional, no caso de recrutamento interno, também é extremamente mais veloz, pois o empregado escolhido através de um recrutamento interno não necessita submeter-se a uma bateria total de testes, levantamento de informações, exames médicos etc. Será necessária somente a mudança de função (ASO), providenciando-se a transferência de um setor para outro;

- "novo" empregado não necessita submeter-se ao treinamento introdutório (treinamento dado a todos os novos funcionários para inteirá-los sobre as informações mais importantes da empresa, segurança, etc.), ganhando com isso, no mínimo, algumas horas ou dias de trabalho produtivo;

- os custos finais do processo de R\&S caem vertiginosamente (quase custo zero);

- a motivação do empregado escolhido nesse processo e dos que o rodeiam atinge e supera os limites da normalidade automaticamente, sem esforço e sem custos. 
Quanto às desvantagens do recrutamento interno, de acordo com Chiavenato (1999), destacam-se as seguintes:

- a organização pode estagnar, perdendo criatividade e inovação;

- $\quad$ se a organização não oferecer as oportunidades de crescimento no momento certo, corre-se o risco de defraudar as expectativas dos colaboradores e pode-se criar, consequentemente, estados de desinteresse, apatia e até levar à demissão;

- pode gerar conflitos de interesses entre pessoas que estão em pé de igualdade para ocupar o mesmo cargo;

- pode provocar nos colaboradores menos capazes, normalmente em cargos de chefia, um sentimento de insegurança que poderá fazer com que estes sufoquem o desempenho e aspirações dos subordinados, a fim de evitarem futura concorrência.

Vale observar que o recrutamento interno não pode ser feito em termos globais dentro da organização, uma vez que só pode ser efetuado à medida que o candidato interno tenha, a curto prazo, condições de igualar a performance do antigo ocupante.

\subsection{Recrutamento externo}

É o processo de captação de recursos humanos no mercado de trabalho, com o objetivo de suprir uma necessidade da empresa no seu quadro de efetivos (Marras, 2009, p. 73-74).

Entre as vantagens do recrutamento externo, conforme Chiavenato (1999) citam-se as seguintes: a celeridade do processo, já que não há outras movimentações adjacentes; a introdução de novas e diferentes ideias, que podem contribuir para o sucesso da empresa; e a construção de uma boa imagem da empresa, uma vez que se mostra interessada e empenhada na aquisição de novos conhecimentos e reforça a imagem de empregadora.

Tal como no recrutamento interno, esta estratégia de recrutamento também apresenta alguns inconvenientes: é mais dispendiosa que o recrutamento interno; representa mais riscos de incompatibilidade entre o trabalhador e a empresa; e pode ser frustrante para os trabalhadores da empresa, uma vez que acaba com as perspectivas de carreira.

Chiavenato (1999) menciona as seguintes desvantagens do recrutamento externo: 
é um processo mais demorado do que o recrutamento interno: temos de considerar o tempo despendido com a escolha das técnicas mais adequadas, com as fontes de recrutamento, com a atração dos candidatos, com a seleção, com os exames médicos, com possíveis compromissos do candidato em outra organização e com o processo de admissão. Este período será maior para as funções de topo;

- desmotiva as pessoas que trabalham na organização: os funcionários podem, em determinados casos, ver o recrutamento externo como uma política de deslealdade para com eles;

- cria distorções ao nível salarial: quem vem de fora normalmente vem ganhar mais do que aquele que já está há mais tempo na organização, embora venha desempenhar a mesma função, o que pode levar ao aumento dos salários em geral, para evitar grandes disparidades;

- é mais caro: exige despesas imediatas com anúncios, jornais, agências de recrutamento;

- é menos seguro do que o recrutamento interno, dado que os candidatos são desconhecidos: apesar das técnicas de seleção, muitas vezes a empresa não tem condições de confirmar as qualificações do candidato; daí submetê-lo a um período experimental, precisamente pela insegurança da empresa relativamente ao processo de recrutamento e seleção.

O desenvolvimento pessoal e empresarial de um colaborador depende de seu aperfeiçoamento e desempenho motivacional próprios, onde a Gestão de Recursos Humanos tem que estar atenta às inovações e proporcionar condições favoráveis para seu crescimento.

\subsection{Seleção de pessoal}

Para Lacombe (2005, p. 79), "a seleção abrange o conjunto de práticas e processos usados para escolher, dentre os candidatos disponíveis, aquele que parece ser o mais adequado para a vaga existente". Por sua vez, Marras (2009, p. 79) destaca que

Seleção de pessoal é uma atividade de responsabilidade do sistema de $\mathrm{ARH}$, que tem por finalidade escolher, sob metodologia, candidatos a emprego recebidos pelo setor de recrutamento, para o atendimento das necessidades internas da empresa.

Uma boa seleção deve dar preferência aos candidatos que possuem habilidades, atitudes e comportamentos requeridos pela empresa e que são difíceis de serem adquiridos por meio de treinamento, como a habilidade de lidar com 
as pessoas, a capacidade de ouvir o interlocutor, de não perder o controle de si, o conhecimento de si próprio, das suas limitações e dos seus pontos fortes, não sendo fácil avaliar com precisão todos esses fatores. Requer-se ainda um amplo universo de candidatos, pois quanto maior o número de concorrentes, maior a probabilidade de se admitir a pessoa certa.

\subsubsection{Processo de seleção}

O papel do selecionador é reconhecer a importância da seleção no contexto da gestão de pessoas, definir critérios para a seleção de pessoas, reconhecer vantagens e limitações dos meios adotados para recrutamento e seleção de pessoas e conduzir entrevistas para selecioná-las. (Gil, 2001, p. 91-92).

\subsubsection{Definição de critérios}

Para que se possa selecionar adequadamente, torna-se necessário definir critérios. Para tanto, requer-se o conhecimento das políticas de seleção da empresa e, sobretudo, dos cargos que se deseja preencher.

Alguns critérios de seleção são os seguintes:

- conhecimentos que a pessoa deve ter;

- experiência e aptidões necessárias (aptidão mecânica, percepção, controle);

- características pessoais necessárias (disciplina, paciência, iniciativa, sociabilidade, etc.).

- circunstâncias pessoais que devem ser consideradas (família, local de residência, posse de automóvel).

Todo processo de seleção de pessoal baseia-se fundamentalmente na análise comparativa de dois campos (Marras, 2009, p. 79):

\begin{tabular}{|c|c|}
\hline Exigência do cargo & Características do candidato \\
\hline $\begin{array}{c}\text { São as características que o cargo } \\
\text { exige do profissional em termos de } \\
\text { conhecimentos, habilidades e atitudes } \\
\text { para o bom desempenho das funções. }\end{array}$ & $\begin{array}{c}\text { É o conjunto de conhecimentos, habilidades } \\
\text { e atitudes que cada candidato possui para } \\
\text { desempenhar suas tarefas. }\end{array}$ \\
\hline
\end{tabular}

Quadro 2 - Campos de análise e seleção

Fonte: adaptado de Marras (2009). 


\subsubsection{Métodos de seleção}

"De modo geral o processo de recrutamento possibilita à organização dispor de um número de candidatos superior à quantidade de cargos a serem preenchidos" (Gil, 2001, p. 98). Existem diversos procedimentos adequados para identificar as características pessoais de cada candidato, com vistas a possibilitar a seleção dos mais aptos. Constituem procedimentos e métodos de seleção:

- análise de currículos;

- competência profissional;

- desejo de permanecer no emprego e de seguir carreira;

- experiência prática;

- adequação ao grupo;

- vontade de trabalhar e de aceitar novos desafios;

- orientação para os lucros e melhoria de desempenho;

- testes escritos;

- testes práticos;

- testes psicológicos;

- entrevista (vantagens e limitações da entrevista, condução da entrevista e o que perguntar).

Tais procedimentos compõem-se de trabalhos de prospecção ou coleta de informações e dados de cada indivíduo, em particular, na tentativa de conhecê-los extrínseca e intrinsecamente. Para possibilitar essa análise dos indivíduos, o selecionador dispõe de dois instrumentos, que são (Marras, 2009, p. 79-80):

- entrevista de seleção;

- testes diversos de aferição.

\subsubsection{Entrevista de seleção}

A entrevista de seleção objetiva detectar dados e informações dos candidatos a emprego, subsidiando a avaliação do processo seletivo. É uma das técnicas de seleção utilizadas nas grandes, médias e pequenas empresas.

Atualmente, entre todos os instrumentos utilizados pelo selecionador, a entrevista de seleção é aquela considerada mais importante. Até alguns anos atrás, contudo, era tida como um instrumento acessório, em uma época em que os testes psicológicos eram mais relevantes que a própria análise pessoal do selecionador. 
Essa situação inverteu-se com o tempo, pois o primado dos testes psicológicos terminou. $O$ elemento substantivo no processo seletivo atual é a análise do selecionador, isto é, a própria entrevista realizada entre candidato e selecionador. Os testes psicológicos e os demais testes estão sendo considerados elementos acessórios, complementares à própria entrevista.

Embora careça de base científica e se situe como a técnica mais subjetiva e imprecisa de seleção, a entrevista pessoal é aquela que mais influencia a decisão final a respeito dos candidatos.

A entrevista pessoal tem outras aplicações, como na triagem inicial do recrutamento, na seleção de pessoal, no aconselhamento e orientação profissional, na avaliação do desempenho, no desligamento etc. Em todas essas aplicações, a entrevista deve ser feita com habilidade e tato, a fim que possa produzir os resultados esperados. Todavia, entrevistar é o método mais amplamente usado em seleção de pessoal. E essa preferência existe, apesar da subjetividade e imprecisão da entrevista. (Chiavenato, 2006, p. 193-194).

Na realidade, a entrevista é o processo de comunicação entre duas ou mais pessoas que interagem. De um lado, está o entrevistador ou entrevistadores e, de outro lado, o entrevistado ou entrevistados. Dentro da abordagem de sistemas, o entrevistado ou candidato se assemelha a uma caixa preta a ser desvendada: aplicam-se a ela determinados estímulos (entradas) para verificar suas reações (saídas) e, com isso, estabelecem-se as possíveis relações de causa e efeito ou verifica-se seu comportamento diante de determinadas situações.

\subsubsection{Importância da seleção}

Como as pessoas constituem o mais importante ativo de que dispõem as organizações, devem ser recrutadas e selecionadas com a maior competência possível, já que falhas nesse processo podem comprometer outras ações de gestão a serem desenvolvidas posteriormente. (Gil, 2001, p. 91).

\section{MÉTODO DE PESQUISA}

O método utilizado nesta pesquisa foi o estudo bibliográfico de caráter exploratório. A principal característica da pesquisa bibliográfica reside no fato de permitir ao investigador a cobertura de uma gama de fenômenos muito mais ampla do que aquela que ele poderia pesquisar diretamente. Essa vantagem torna-se particularmente importante quando o problema de pesquisa requer dados muito dispersos 
pelo espaço e tempo. A pesquisa bibliográfica também é indispensável nos estudos históricos. Em muitas situações, não há outra maneira de conhecer os fatos passados, se não com base em dados bibliográficos, segundo bem salientou Gil (2002).

Foram levantados dados científicos no que tange à gestão no recrutamento e seleção de pessoal nas organizações, bem como seus conceitos, técnicas e processos no cenário de negócios empresariais. Busca-se, com este estudo, levantar dados relevantes sobre a temática abordada, mediante a contemplação de artigos, livros, autores, dissertações/teses, periódicos especializados, acervos de bibliotecas e bases de dados de ordem acadêmica. O levantamento de informações e de dados atualizados visa problematizar a importância da gestão estratégica de recrutamento e seleção de pessoal nas organizações.

\section{CONSIDERAÇÕES FINAIS}

A importância do recrutamento e seleção dentro de uma organização está em trazer para dentro da empresa profissionais qualificados e preparados para exercer suas funções, com melhor desempenho e maior produtividade na aplicação de conhecimentos e habilidades em suas atividades.

Pode-se afirmar que o recrutamento e a seleção em uma empresa apoiamse nos demais setores da instituição e, sendo forem realizados de maneira correta, evitam-se os turnovers e custos adicionais à organização.

Portanto o estudo, a análise e a verificação dos procedimentos de recrutamento e seleção de uma empresa implicam seu desenvolvimento organizacional, compreendendo os passos e os devidos critérios de sua existência dentro da organização.

Essa análise do recrutamento e seleção dentro das empresas muitas vezes é feita de forma funcional, em que a teoria e o requinte de conhecimento ficam esquecidos. Porém, se o trabalho é realizado de forma adequada à situação e sem o comodismo do passado, pode-se sim ter mais qualidade no momento de se unir a prática com a teoria.

Não se pode jamais esquecer que tudo isso só pode ser feito através das pessoas - principais elementos de uma empresa. Estas, por sua vez, devem ter preparação, entrosamento e capacidade para realizar suas funções. Deve-se manter sempre um clima ou ambiente motivacional positivo e aberto às novidades; caso contrário, as atividades poderão não funcionar.

Com o mercado competitivo e o capital intelectual sendo o maior investimento, as organizações devem garantir mais qualidade e profissionalismo em seu recrutamento e seleção, tendo em vista o futuro da instituição. 
Assim, busca-se erradicar uma série de falhas que podem comprometer o processo de contratação, como também detectar os valores do profissional, os quais poderão, num futuro próximo, ser transformados em competência essencial para a empresa. Um exemplo de benefício da fase de seleção é a verificação do nível de resiliência do candidato, ou seja, a sua aptidão para não só se adaptar a novas situações, como também para prosperar durante as mudanças, reagindo prontamente a elas.

\section{REFERÊNCIAS}

Chiavenato, I. (1999). Administração de Recursos Humanos: Fundamentos básicos. (4. ed.). São Paulo: Atlas.

Chiavenato, I. (2006) Recursos humanos: O capital humano das organizações. (8. ed.). São Paulo: Atlas.

Chiavenato, I. (2002). Recursos Humanos. (7. ed.). São Paulo: Atlas.

Gil, A. C. (2001). Gestão de Pessoas: Enfoque nos papeis profissionais. São Paulo. Atlas.

Gil, A. C. (2002). Como elaborar projetos de pesquisa. São Paulo: Atlas.

Lacombe, F. J. M. (2005). Recursos Humanos: Princípios e tendências. São Paulo: Saraiva.

Marras, J. P. (2009). Administração de Recursos Humanos: Do operacional ao estratégico. (13. ed.). São Paulo: Saraiva. 